\title{
The Effect of Elevation on Volumetric Measurements of the Lower Extremity
}

\author{
Cordial M. Gillette ${ }^{1 *}$, Scott T. Doberstein ${ }^{2}$, Danielle L. DeSerano ${ }^{3}$, Eric J. Linnell ${ }^{4}$ \\ ${ }^{1}$ Exercise and Sport Science, University of Wisconsin - La Crosse, 1725 State Street, 148 Mitchell Hall, La Crosse, Wisconsin, 54601, USA \\ ${ }^{2}$ Exercise and Sport Science, University of Wisconsin - La Crosse, 1725 State Street, 144 Mitchell Hall, La Crosse, Wisconsin, 54601, USA \\ ${ }^{3}$ UW-Health Sports Medicine, 621 Research Drive, Madison, Wisconsin, 53711, USA \\ ${ }^{4}$ Athletics, University of Wisconsin-Madison, 1440 Monroe Street, Madison, Wisconsin, 53711, USA
}

Corresponding Author: Cordial M. Gillette, E-mail: cgillette@uwlax.edu

\section{ARTICLE INFO}

Article history

Received: May 29, 2017

Accepted: July 08, 2017

Published: July 31, 2017

Volume: 5 Issue: 3

Conflicts of interest: None

Funding: None

\begin{abstract}
Background: The empirical evidence for the use of RICE (rest, ice, compression, elevation) has been questioned regarding its clinical effectiveness. The component of RICE that has the least literature regarding its effectiveness is elevation. Objective: The objective of this study was to determine if various positions of elevation result in volumetric changes of the lower extremity. Methodology: A randomized crossover design was used to determine the effects of the four following conditions on volumetric changes of the lower extremity: seated at the end of a table (seated), lying supine (flat), lying supine with the foot elevated 12 inches off the table (elevated), and lying prone with the knees bent to 90 degrees (prone). The conditions were randomized using a Latin Square. Each subject completed all conditions with at least 24 hours between each session. Pre and post volumetric measurements were taken using a volumetric tank. The subject was placed in one of the four described testing positions for 30 minutes. The change in weight of the displaced water was the main outcome measure. The data was analyzed using an ANOVA of the pre and post measurements with a Bonferroni post hoc analysis. The level of significance was set at $P<.05$ for all analyses. Results: The only statistically significant difference was between the gravity dependent position (seated) and all other positions ( $\mathrm{p}<.001)$. There was no significant difference between lying supine (flat), on a bolster (elevated), or prone with the knees flexed to 90 degrees (prone). Conclusions: From these results, the extent of elevation does not appear to have an effect on changes in low leg volume. Elevation above the heart did not significantly improve reduction in limb volume, but removing the limb from a gravity dependent position might be beneficial.
\end{abstract}

Key words: Swelling, Injury, Edema, Treatment

\section{INTRODUCTION}

For many decades, the use of rest, ice, compression, and elevation (RICE) has been the main-stay and a widely accepted treatment for acute musculoskeletal injuries. The proposed mechanisms for assisting in the healing process are to limit the various unwanted cellular changes that occur with injury and thus decrease the amount and extent of tissue damage. In theory, this would lead to quicker healing and a faster return to normal function and activity levels. However, RICE has been questioned regarding its clinical effectiveness based on the limited evidence available to date (van den Bekerom et al., 2012). Of all the components of RICE, ice has been researched the most extensively and thus clinicians practice injury management based on very good evidence related to its use for acute injuries (Jutte, Merrick, Ingersoll, \& Edwards, 2001; Merrick, Jutte, \& Smith, 2003; Merrick, Knight, Ingersoll, \& Potteiger, 1993; Merrick, Rankin, Andres, \&
Hinman, 1999; Otte, Merrick, Ingersoll, \& Cordova, 2002; Prentice, 2009a). Greenwood and Gillette (2017), however, showed that cold water immersion increases metabolic rate in humans and therefore is more beneficial for exercise recovery than treatment of acute injuries. Even though it is very common for injuries to be elevated during acute treatment and makes sense theoretically, the empirical evidence supporting its use is lacking, so much so that some clinicians question using this part of the RICE protocol at all. Several questions regarding the use of elevation include is there a most beneficial degree of elevation or is elevation even necessary?

Elevation is utilized based on theories that it will eliminate the effects of gravity, augment venous return (Hirai \& Iwata, 2004), assist lymphatic drainage of blood and other fluids (Prentice, 2009b, 2009c, 2011, 2013), and decrease capillary hydrostatic pressure (Knight, 1995; Warren, Hardi- 
man, \& Woolf, 1992). There is limited and conflicting evidence on the effects of venous return and lymphatic drainage in regards to elevation (Elkins, Herrick, Grindlay, Mann, \& De Forest, 1953; Hirai \& Iwata, 2004; Warren et al., 1992). The leading theory for the use of elevation is to decrease capillary hydrostatic pressure thereby decreasing the loss of fluid across the capillary (Merrick et al., 1993) and potentially limit fluid accumulation in the extremity. While there is evidence of changes in capillary hydrostatic pressures and significant changes in the volume of lower legs after 4 hours (Hargens, 1983), the window of opportunity for limiting secondary injury lies within the first 30 minutes following acute injury (Merrick \& McBrier, 2010) and there is currently no evidence for volume changes due to elevation over a $30 \mathrm{~min}$ ute time period. Therefore, there is a need to examine volume changes in the lower extremity over a 30 minute time period and determine if limb position affects volumetric changes. To determine changes in limb volume due to elevation, the effects of multiple positions must first be determined in a non-edematous limb. The objective of this study was to determine if various positions of elevation result in volumetric changes of the lower extremity of non-injured individuals in a 30 minute window. The hypothesis was positions of elevation would cause greater decreases in volumetric measurements than a non-elevated or gravity dependent position.

\section{METHODOLOGY}

\section{Participants}

The subjects included 21 healthy, college-aged student volunteers (9 males, 12 females) ages $19-22$ with an average age of 21.05 (males - 21.00; females - 21.09) and no previous ( 6 month) history of low leg injury. The average height, weight, and BMI were $174.18 \mathrm{~cm}$ (males $-176.16 \mathrm{~cm}$; females $-172.20 \mathrm{~cm}$ ), $74.11 \mathrm{~kg}$ (males $-77.4 \mathrm{~kg}$; females $70.82 \mathrm{~kg}$ ), and 24.36 (males - 24.82; females - 23.91), respectively.

\section{Study Design}

A randomized crossover design was used to determine the effects of the four following conditions on volumetric changes of the lower extremity: seated at the end of a table (seated, Figure 1), lying supine (flat, Figure 2), lying supine with the foot elevated 12 inches off the table (elevated, Figure 3), and lying prone with the knees bent to 90 degrees (prone, Figure 4). The conditions were randomized using a Latin Square. Each subject completed all conditions with at least 24 hours between each condition session.

\section{Volumetric Measurements}

Pre and post volumetric measurements were taken using a volumetric tank. The volumetric tank had been modified to position the overflow spout parallel to the floor. The beginning weight of the volumetric tank and water was $9000 \mathrm{~g}$ (Figure 5) using a Mettler Toledo XS32000L Precision Balance (Columbus, $\mathrm{OH}$ ). The volumetric tank was transferred to the floor without loss of water and the collection container was placed under the spout. The subject was seated in a chair to allow proper positioning of the foot in the tank. Before placing the subject's right foot in the volumetric tank, it was wiped with a wet towel to avoid absorption of any water through the skin and air bubbles from accumulating on the skin. The subject's foot and ankle were submersed in the vol-

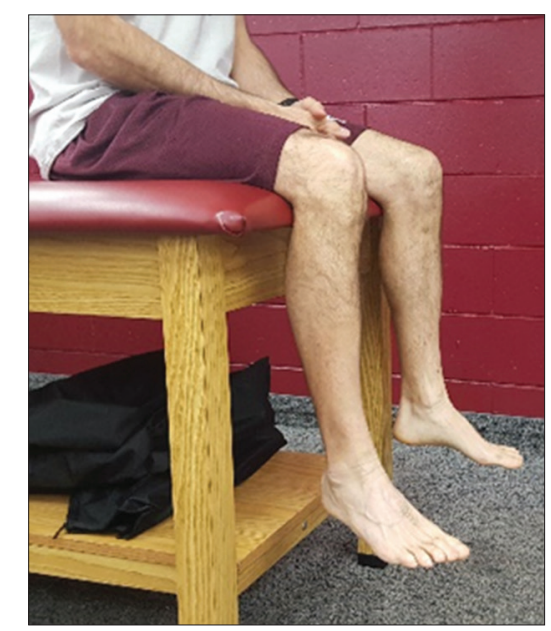

Figure 1. Seated

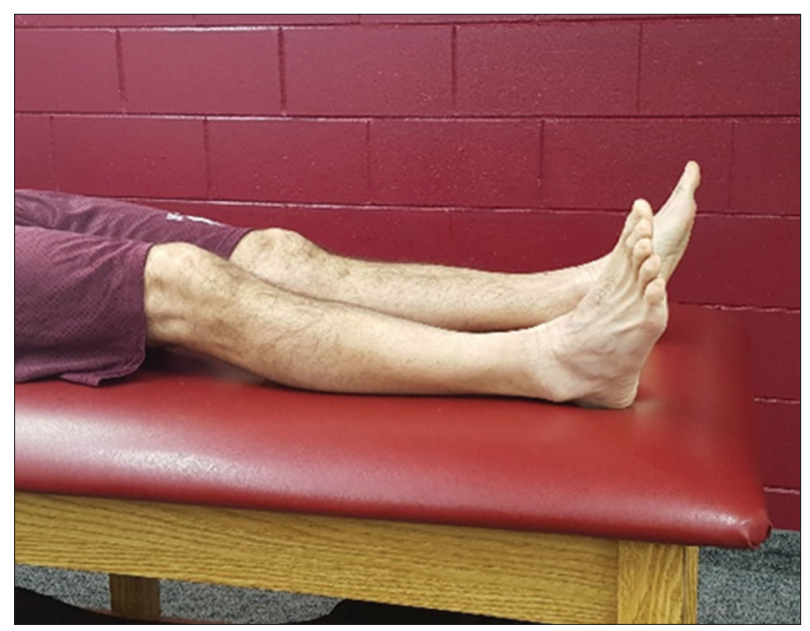

Figure 2. Lying Supine

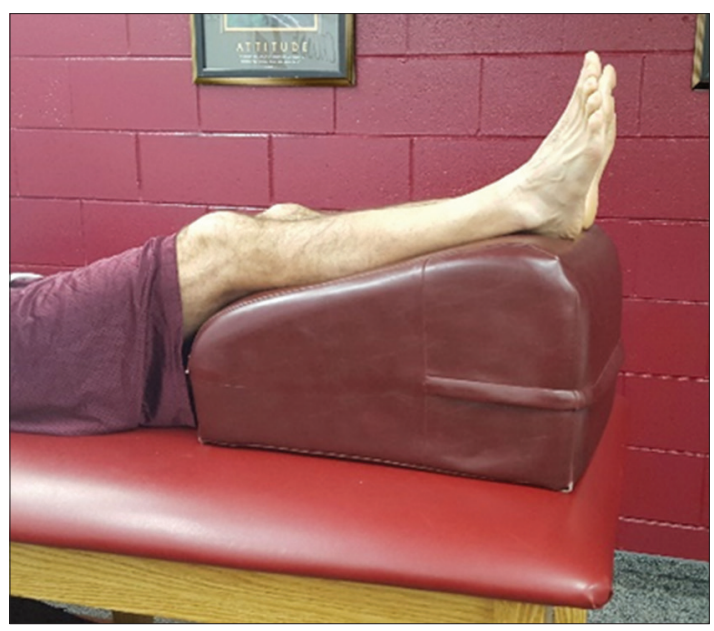

Figure 3. Elevated 12 inches 
umetric tank and they were instructed to place the MP joint of their great toe and medial malleolus against the side wall and their heel and low leg against the back wall of the tank. The subject remained seated with their foot in the tank while the water was collected in the container until dripping from the spout ceased (Figure 6). The collection container and displaced water were again weighed (Figure 7). This measurement was taken before and after each condition.

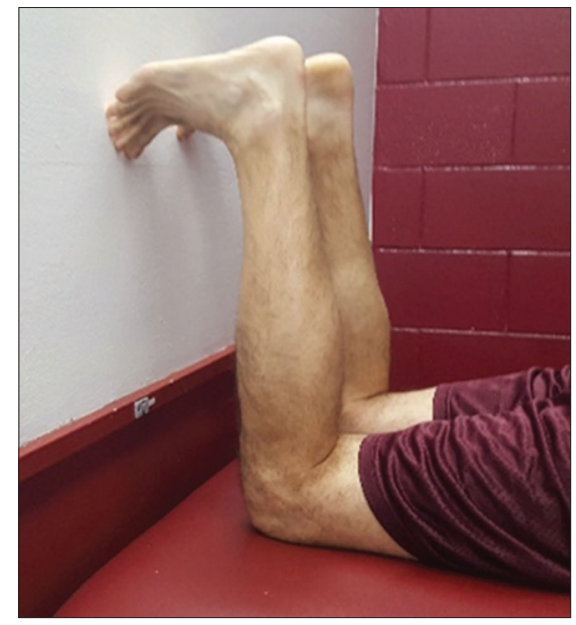

Figure 4. Prone with knees at 90 degrees

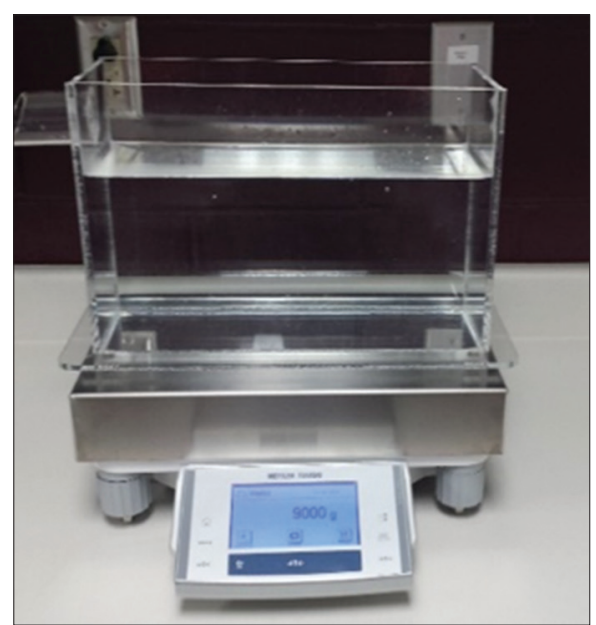

Figure 5. Beginning volume

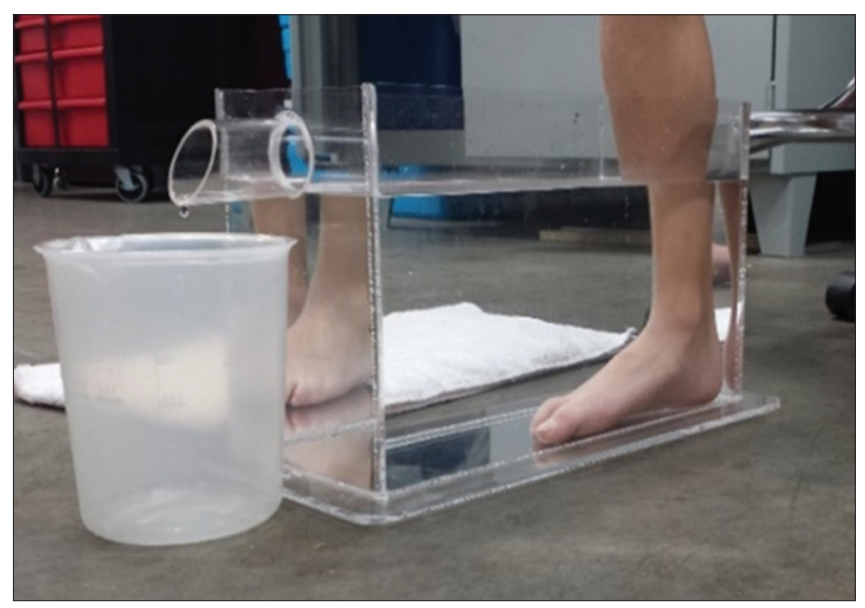

Figure 6. Foot placed in tank for collection

\section{Testing Positions}

After the initial volumetric measurement was taken, the subject was placed in one of the four testing positions as described above. They remained in this position for 30 minutes and were instructed to avoid movement (i.e. dorsiflexion/ plantarflexion, toe flexion/extension, etc.) throughout the 30 minutes. Upon completion of the intervention, the post volumetric measurement was taken utilizing the above described procedures.

\section{Statistical Analysis}

The change in weight of the displaced water was the main outcome measure. The data was normally distributed. The data was analyzed using a paired samples t-test of the pre and post measurements as well as an ANOVA of the mean change in pre and post measurements with a Bonferroni post hoc analysis. The level of significance was set at $P<.05$ for all analyses. Statistical analysis was performed with SPSS version 23.

\section{RESULTS}

The paired samples t-test indicated significant changes in volume from pre to post-test volumetric measurements for all positions except for the seated position (seated, $\mathrm{p}=.087$; supine, $\mathrm{p}=.001$; elevated 12 inches, $\mathrm{p}=.004$; prone, $\mathrm{p}=.002$ ). The seated, gravity-dependent position was the only position which caused a mean increase in volume; all other positions demonstrated decreases in volume, including the neutral position. The ANOVA revealed the difference was significant between the gravity dependent position (seated) and all other positions (seated, $\mathrm{p}=.003$; elevated 12 inches, $\mathrm{p}=.037$, prone at $90, \mathrm{p}=.004)$. There was no significant difference between lying supine (flat), with the foot elevated 12 inches while in a supine position (elevated), $\mathrm{p}=1.00$, or prone with the knees flexed to 90 degrees (prone), $\mathrm{p}=1.00$; nor was there a difference between the elevated position and prone, $\mathrm{p}=.611$. The volumetric changes based on positioning are presented in Table 1.

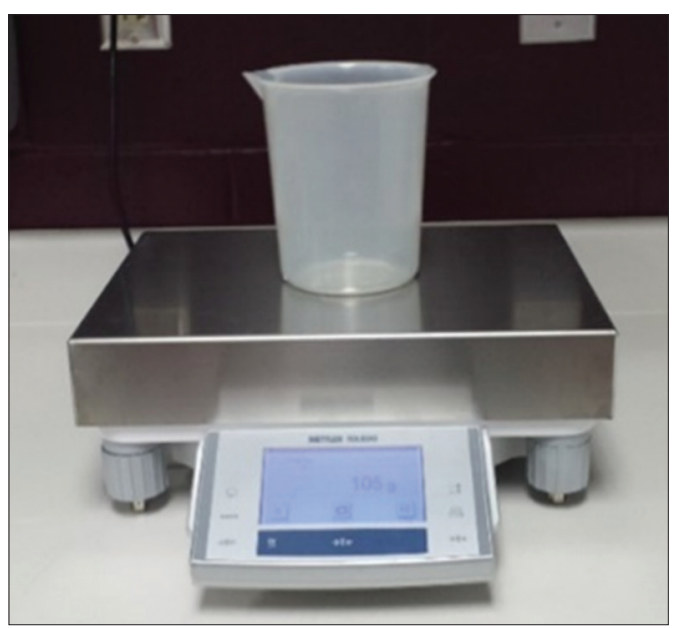

Figure 7. Displaced water 
Table 1. Volumetric changes in the low leg

\begin{tabular}{lccc}
\hline Position & \multicolumn{2}{c}{ Mean \pm SD } & $\begin{array}{c}\text { Mean change in } \\
\text { volume } \pm \text { standard } \\
\text { error }\end{array}$ \\
\cline { 2 - 4 } & Pre-test & Post-test & $11.7 \pm 6.47$ \\
\hline Seated & $510.4 \pm 148.2$ & $522.1 \pm 152.7$ & $-14.3 \pm 3.58^{*}$ \\
$\begin{array}{l}\text { Supine } \\
\text { flat) }\end{array}$ & $518.7 \pm 159.5$ & $504.3 \pm 160.1$ & $-9.3 \pm 2.83^{*}$ \\
$\begin{array}{l}\text { Elevated } \\
12 \text { inches }\end{array}$ & $511.5 \pm 164.3$ & $502.2 \pm 164.4$ & \\
$\begin{array}{l}\text { Prone at } \\
90\end{array}$ & $525.9 \pm 168.7$ & $509.6 \pm 162.9$ & $-16.3 \pm 4.46^{*}$ \\
\hline
\end{tabular}

*Denotes significant change compared to baseline $(\mathrm{p}<0.05)$.

\section{DISCUSSION}

The results of this study indicate elevated positions did not have a greater decrease in limb volume than a neutral or gravity dependent positon. The recommended extent of elevation, based on expert opinion is 15 to 25 centimeters (6-10 inches) above the heart (Knight, 1995). It is reasonable to state that elevation above the heart is not necessary for removing edema, while removing the limb from a gravity dependent position might be beneficial. Several texts (Prentice, 2009a, 2009c, 2011, 2013) indicate the higher the elevation, the greater the effect; however, Warren et al.(1992) assessed volume changes in human calves during 45 and 90 degrees of elevation using strain gauge plethysmography and found the higher angle produced slower exsanguination with greater venous return when the lower leg was elevated to 45 . Therefore, a greater degree of elevation may not promote greater results in preventing or removing edema. In our study, the 90 degree position (prone) did demonstrate the greatest change in volume, but it was not significant.

These results are comparable to those found by Tsang et al.(2000) in which significant changes in limb volume were found after 30 minutes of elevation in healthy individuals. At 90 degrees of elevation in a supine position, their study showed a volumetric decrease of $15.3 \mathrm{~mL}$ immediately post treatment while we found volumetric decreases of $16.3 \mathrm{~mL}$ in a prone position with the knee bent to 90 degrees. Their study also showed a continued decrease in limb volume of $9.8 \mathrm{~mL} 60$ minutes after returning to a gravity dependent position. They reported that elevation does decrease volume due to increases in venous flow and lymphatic absorption of interstitial fluid; however, only one position was studied. We did not look at results other than immediately following the intervention; therefore, the duration of the effect of removing gravity cannot be concluded from our study, but perhaps repeating this study with varying degrees of elevation may be useful given the findings of Warren et al.(1992). A follow-up study by Tsang et al. (2003) looked at the effects of returning to a gravity-dependent position following elevation and intermittent compression on injured ankles and revealed elevation alone, or elevation and intermittent compression did not produce decreased ankle volume for an extended period of time. While they did find significant decreases in volume immediately post treatment, the effects were negated when the limb returned to a gravity-dependent position, yet 60 minutes in a gravity-dependent position did not increase the volume beyond baseline measurements. Our results were also consistent with Sims (1986) who examined ankle volume changes in healthy, uninjured ankles in an elevated position compared to a gravity dependent position. He found a $14-17 \mathrm{~mL}$ decrease in volume in an elevated position compared to a 16 to $18 \mathrm{ml}$ increase in a gravity dependent position. Sims (Sims, 1986) attributed changes in position to gravity's effect on the lymphatic system. The question still remains if there are greater effects on venous return or lymphatic flow. Hirai and Iwata (2004) investigated peak femoral venous velocity and calf muscle volume before and during limb elevation, deep respiration, calf compression and various types of leg exercises. They found that while elevation did promote venous return, active exercise utilizing ankle plantar and dorsiflexion was more effective to promote venous return (Hirai \& Iwata, 2004). This supports the use of early, pain-free range of motion exercises following acute injury.

\section{CONCLUSION}

From these results, the extent of elevation does not appear to have an effect on changes in low leg volume. This study was conducted on healthy individuals and more information is needed to determine if these effects would occur in an individual with swelling. Given these results, elevation is not harmful to the patient, yet its benefit is not clearly evident.

A limitation of all the studies conducted on elevation thus far is that we have examined volume changes on either healthy subjects or post-acute injury. An attempt to determine the effects of elevation on the formation of edema in acute lateral ankle sprains was made by Hageman (2006), but no injuries meeting the inclusion criteria occurred or were brought to the attention of the investigator. It is, therefore, difficult to determine the potential of elevation to prevent edema from accumulating in an injured limb. A limitation of this study was that it was conducted on healthy individuals with no swelling. A recommendation for a future study would be to repeat these procedures on individuals with swelling or simulated swelling. In conclusion, further evidence must be sought to elucidate the significance of elevation. If our treatment goal is to limit secondary injury and prevent edema formation, yet treatments in a gravity dependent position, such as ice immersion, may be more useful to limit secondary injury through tissue temperature decrease, the question remains if there is enough evidence to keep elevation as a main-stay in acute injury management.

\section{REFERENCES}

Elkins, E. C., Herrick, J. F., Grindlay, J. H., Mann, F. C., \& De Forest, R. E. (1953). Effect of various procedures on the flow of lymph. Archives of Physical Medicine and Rehabilitation, 34(1), 31-39.

Greenwood, A., \& Gillette, C. (2017). Effect of cold water immersion on metabolic rate in humans. International Journal of Kinesiology and Sports Science, 5(2), 1 - 6. 
doi: doi:10.7575/aiac.ijkss.v.5n.2p.1

Hargens, A. R. (1983). Fluid shifts in vascular and extravascular spaces during and after simulated weightlessness. Medicine \& Science in Sports \& Exercise, 15(5), 421-427.

Hirai, M., \& Iwata, H. (2004). A comparison of physical methods for prophylaxis of deep vein thrombosis on augmentation of venous flow velocity and reduction of calf volume. Phlebology, 19(2), 72-76. doi:10.1258/026835504323080344

Jutte, L. S., Merrick, M. A., Ingersoll, C. D., \& Edwards, J. E. (2001). The relationship between intramuscular temperature, skin temperature, and adipose thickness during cryotherapy and rewarming. Archives of Physical Medicine and Rehabilitation, 82(6), 845-850. doi: http://dx. doi.org/10.1053/apmr.2001.23195

Knight, K. (1995). Cryotherapy in sport injury management. Champaign, IL: Human Kinetics.

Merrick, M. A., Jutte, L. S., \& Smith, M. E. (2003). Cold modalities with different thermodynamic properties produce different surface and intramuscular temperatures. Journal of Athletic Training, 38(1), 28-33.

Merrick, M. A., Knight, K. L., Ingersoll, C. D., \& Potteiger, J. A. (1993). The effects of ice and compression wraps on intramuscular temperatures at various depths. Journal of Athletic Training, 28(3), 236-245.

Merrick, M. A., \& McBrier, N. M. (2010). Progression of secondary injury after musculoskeletal trauma-A window of opportunity? Journal of Sport Rehabilitation, 19, 380-388.

Merrick, M. A., Rankin, J. M., Andres, F. A., \& Hinman, C. L. (1999). A preliminary examination of cryotherapy and secondary injury in skeletal muscle. Medicine \& Science in Sports \& Exercise, 31(11), 1516-1521.

Otte, J. W., Merrick, M. A., Ingersoll, C. D., \& Cordova, M. L. (2002). Subcutaneous adipose tissue thickness alters cooling time during cryotherapy. Archives in $P$ hysical Medicine and Rehabilitation, 83(11), 1501-1505. doi: http://dx.doi.org/10.1053/apmr.2002.34833

Prentice, W. E. (2009a). Arnheim's Principles of Athletic Training (13 ed.). Boston, MA: McGraw-Hill.

Prentice, W. E. (2009b). Arnheim's Principles of Athletic Training: A Competency-Based Approach (M. Ryan Ed. $13^{\text {th }}$ ed.). New York, NY: McGraw-Hill.

Prentice, W. E. (2009c). Therapeutic Modalities for Sports Medicine and Athletic Training (6th ed.). Boston, MA: McGraw-Hill.

Prentice, W. E. (2011). Rehabilitation Techniques for Sports Medicine and Athletic Training (5th ed.). New York, NY: McGraw Hill.

Prentice, W. E. (2013). Essentials of Athletic Injury Management (10e ed.). New York, NY: McGraw-Hill.

Sims, D. (1986). Effects of positioning on ankle edema. The Journal of Orthopedic and Sports Physical Therapy, 8(1), 30-33.

van den Bekerom, M. P., Struijs, P. A., Blankevoort, L., Welling, L., van Dijk, C. N., \& Kerkhoffs, G. M. (2012). What is the evidence for rest, ice, compression, and elevation therapy in the treatment of ankle sprains in adults? Journal of Athletic Training, 47(4), 435-443. doi:10.4085/1062-6050-47.4.14

Warren, P. J., Hardiman, P. J., \& Woolf, V. J. (1992). Limb exsanguination. II. The leg: effect of angle of elevation. Annals of the Royal College of the Surgeons of England, 74(5), 323-325. 